\title{
Prevalence of anemia and its associated factors among married women in 19 sub- Saharan African countries
}

Betregiorgis Zegeye ${ }^{1}$, Felix Emeka Anyiam², Bright Opoku Ahinkorah ${ }^{3}$, Edward Kwabena Ameyaw ${ }^{3}$, Eugene Budu ${ }^{4}$, Abdul-Aziz Seidu ${ }^{4}$ and Sanni Yaya ${ }^{5,6^{*}}$ (i)

\begin{abstract}
Background: Sub-Saharan Africa (SSA) remains the region with the highest burden of anemia globally. Since anemia has both health and non-health-related consequences, its reduction is one of the Sustainable Development Goals. Therefore, this study aimed to examine the prevalence of anemia and its associated factors among married women in SSA.

Methods: Using Stata version-14 software, the analysis was done on 89,029 married women from the Demographic and Health Surveys of 19 countries in SSA. Pearson Chi-Square test and Binary logistic regression analyses were used to examine the factors associated with anemia. The results were presented using adjusted Odds Ratio (aOR) at a 95\% Confidence Interval (CI). A $p$-value less than or equal to $0.05(p \leq 0.05)$ was considered statistically significant.

Results: The pooled analysis showed that $49.7 \%$ of married women were anemic. Of these, $1.04 \%$ and $15.05 \%$ were severely and moderately anemic respectively, and the rest $33.61 \%$ were mildly anemic. Husband education (primary school-aOR $=0.84,95 \% \mathrm{Cl} ; 0.71-0.99$ ), wealth index (middle-aOR $=0.81,95 \% \mathrm{Cl} ; 0.68-0.96$, richer-aOR $=0.69,95 \% \mathrm{Cl}$; $0.57-0.84$, richest-aOR $=0.68,95 \% \mathrm{Cl} ; 0.51-0.91$ ), modern contraceptive use (yes-aOR $=0.68,95 \% \mathrm{Cl} ; 0.56-0.81$ ) and religion (Muslim-aOR $=1.27,95 \% \mathrm{Cl} ; 1.11-1.46$, others-aOR $=0.73,95 \% \mathrm{Cl} ; 0.59-0.90$ ) were factors associated with anemia among married women.

Conclusion: The findings show that nearly half of the married women are affected by anemia. Enhancing partners' educational levels, and economic empowerment of women, strengthening family planning services, and working with religious leaders to reduce the perception and religious beliefs related to food restrictions can be the main focus to reduce the burden of anemia among married women in SSA.
\end{abstract}

Keywords: Anemia, Factors, Sub-Saharan Africa, Married women, DHS, Global health

\footnotetext{
* Correspondence: sanni.yaya@uottawa.ca

${ }^{5}$ School of International Development and Global Studies, University of Ottawa, Ottawa, Ontario, Canada

${ }^{6}$ The George Institute for Global Health, Imperial College London, London, UK

Full list of author information is available at the end of the article
}

(c) The Author(s). 2021 Open Access This article is licensed under a Creative Commons Attribution 4.0 International License, which permits use, sharing, adaptation, distribution and reproduction in any medium or format, as long as you give appropriate credit to the original author(s) and the source, provide a link to the Creative Commons licence, and indicate if changes were made. The images or other third party material in this article are included in the article's Creative Commons licence, unless indicated otherwise in a credit line to the material. If material is not included in the article's Creative Commons licence and your intended use is not permitted by statutory regulation or exceeds the permitted use, you will need to obtain permission directly from the copyright holder. To view a copy of this licence, visit http://creativecommons.org/licenses/by/4.0/. The Creative Commons Public Domain Dedication waiver (http://creativecommons.org/publicdomain/zero/1.0/) applies to the data made available in this article, unless otherwise stated in a credit line to the data. 


\section{Background}

Anemia is one of the common and major public health and nutritional problems globally [1-3]. The World Health Organization (WHO) defines anemia as a condition in which the number of red blood cells (oxygen caring capacity) is not adequate to meet the body's physiologic needs [1,2, 4]. Globally, anemia affects about two billion people, or one-third of the adult population lives [5-7]. Of these, half a billion are reproductive age women (15-49 years) [8]. According to the 2016 World Bank evidence, $33 \%$ of women in the reproductive-age groups were anemic worldwide [9]. In low and middleincome countries, nearly $35.4 \%$ of reproductive age women were anemic as of 2016 [9]. However, the prevalence of anemia in sub-Saharan African countries increased to $39 \%$ in the same period [9].

Women are among the vulnerable groups mainly due to the experience of menstruation, and pregnancy and childbirth-related blood loss [2]. Anemia among reproductive-age women can be caused by nutritional and non-nutritional causes [10-14]. Anemia leads to dizziness, and fatigue, poor health, and productivity among the general population [15]. The consequence of anemia is high especially among pregnant women because it increases the chances of developing complications for the women and the neonate that could include miscarriage, intrauterine fetal death, preterm delivery, low birth weight, and mortality [16, 17]. Anemia has non-health-related consequences such as high health-care expenditures, decreasing income, and related socio-economic problems among families and communities have also been documented [18].

Hence, emphasis on the reduction of anemia prevalence among reproductive-age women is essential and has a multidimensional and intergenerational importance in enhancing healthier pregnancy, women's and child health, school performance, productivity, and development in general [18-20]. Anemia reduction is one of the Sustainable Development Goals (SDGs) [21] and the World Health Assembly Nutrition Targets for 2025 [22]. Progress in the reduction of anemia has been seen globally and in African countries, however, reduction in anemia prevalence is not on track as targeted by World Health Assembly, i.e. $50 \%$ reduction among reproductive-aged women by 2025 [22].

There are few studies in African countries that show that individual and community level factors were linked with anemia among reproductive-age women [23-28]. However, these studies are either single country [23-27] or in East African countries alone [28]. Therefore, limited evidence on anemia at the sub-regional level is lacking. Hence, we examined the prevalence and factors associated with anemia among married women in sub-
Saharan Africa (SSA). The findings from the present study could help policymakers and programme implementers to review the implementation of anemia reduction strategies and interventions and to speed-up anemia reduction targets by the World Health Assembly [22] and SDGs [21] at the national and regional levels.

\section{Methods}

\section{Data source}

We used data from the Demographic and Health Surveys (DHSs) of 19 sub-Saharan African countries, that were conducted between 2010 and 2019. DHS is a nationally representative survey that is carried out across several low- and middle-income countries and focus on data collection on several demographic and health indicators including anemia [29]. It is carried out with the financial and technical support of the United States Aid for International Development (USAID) and Inner City Fund (ICF) International respectively [30].

DHSs have applied a two-stage stratified cluster sampling technique. In the first stage, Enumeration Areas (EAs) were selected using Probability Proportional to Size (PPS) and in the second stage, fixed number of households (usually 25-30 households) are selected using systematic sampling technique, from the selected EA [31]. We used the individual recode (IR) file for this analysis and a total of 89,029 married women were included for the analysis (see Table 1). The dataset is freely available for download at https://dhsprogram.com/data/available-datasets.cfm. We followed the guidelines for Strengthening Observational studies in Epidemiology (STROBE) during the preparation of this manuscript [32].

\section{Study variables \\ Outcome variable}

The outcome variable for this study was the prevalence of anemia among married women. For non-pregnant women, anemia was defined as hemoglobin count less than $12.0 \mathrm{~g}$ per deciliter $(\mathrm{g} / \mathrm{dl})$ and less than $11.0 \mathrm{~g} / \mathrm{dl}$ for pregnant women. Mild anemia for non-pregnant women was defined as hemoglobin count between 10.0 and 11.9 $\mathrm{g} / \mathrm{dl}$ and for pregnant women between 10.0 and $10.9 \mathrm{~g} /$ dl. Moderate anemia for both pregnant and nonpregnant women was defined as hemoglobin count between 7.0 and $9.9 \mathrm{~g} / \mathrm{dl}$. Severe anemia was defined as a hemoglobin count less than $7.0 \mathrm{~g} / \mathrm{dl}[8,18]$.

\section{Explanatory variables}

With reference to previous studies [11-15, 23-28], we included the following explanatory variables due to their association with anemia among women. These were women's age in years $(15-19,20-24,25-30,31-$ 34, 35-40, 41-44, 45-49), women's educational level (no formal education, primary school, secondary school and 
Table 1 Year of the survey and weighted sample of each studied country

\begin{tabular}{lll}
\hline Country & Year of survey & Weighted sample \\
\hline Burkina Faso & 2010 & 6570 \\
Benin & $2017 / 18$ & 5654 \\
Burundi & $2016 / 17$ & 4703 \\
Congo Democratic Republic & $2013 / 14$ & 6155 \\
Cote d'Ivoire & $2011 / 12$ & 3006 \\
Cameroon & $2018 / 19$ & 3786 \\
Ethiopia & 2016 & 9220 \\
Gabon & 2012 & 3140 \\
Ghana & 2014 & 2745 \\
Gambia & 2013 & 3119 \\
Guinea & 2018 & 3767 \\
Mali & 2018 & 4060 \\
Malawi & $2015 / 16$ & 5232 \\
Rwanda & $2014 / 15$ & 3384 \\
Sierra Leone & 2019 & 4602 \\
Togo & $2013 / 14$ & 3210 \\
Uganda & 2016 & 3745 \\
Zambia & $2018 / 19$ & 7361 \\
Zimbabwe & 2015 & 5570 \\
Total & & $\mathbf{8 9 , 0 2 9}$ \\
\hline
\end{tabular}

higher), husband's educational level (no formal education, primary school, secondary school, higher), women's occupation (not working, professional or technical or managerial, agricultural, manual, others) and wealth index (poorest, poor, middle, rich, richest). Additionally, we included place of residence (urban, rural), reading newspaper (no, yes), listening to radio (no, yes), watching television (no, yes), sex of household head (male, female), decision making capacity (no, yes), wife beating attitude (accept/justify, disagree/not justify), parity (zero, $1-2,3-4,5+)$, family size $(<5,5+)$, barriers to healthcare access (no, yes), improved sanitation (no, yes), religion (Christian, Muslim, others) and contraceptive use (no, yes).

\section{Statistical analyses}

The analysis for this study was carried out using the following steps. First, descriptive analyses such as frequency distribution and percentages were used to show the prevalence of anemia. Pearsons Chi-Square test was used to test for proportional difference between the explanatory variables and anemia and Bivariate logistic regression analysis was used to examine the crude odds of each explanatory variable with the outcome variable. Multicollinearity test was carried out to examine whether or not collinearity among the explanatory variables existed using Variance Inflation Factor (VIF) and we confirmed that there was no evidence of collinearity $($ VIF Mean $=1.96$, VIF Min $=1.08$, Max VIF $=$ 3.15). Finally, all statistically significant explanatory variables in the bivariate logistic regression were entered into a Multivariate logistic regression model. The adequacy of the model was checked by Hosmer-Lemeshow and there was confirmation that the model was a good fit $(P$-value $=0.9497)$. The results were presented using crude odds ratio (cOR) and adjusted odds ratio (aOR) with a 95\% Confidence Interval (CI). A P-value less than or equal to $0.05(p \leq 0.05)$ was considered statistically significant. To take care of the complex nature of the DHS's data, we used the "svyset" command during the analysis, and all three design elements such as weight, cluster, and strata were taken into consideration.

\section{Ethical clearance}

We used secondary data that are publicly available (https://dhsprogram.com/data/available-datasets.cfm).

Ethical procedures are the responsibility of institutions that funded, commissioned, and managed the surveys, and so further ethical clearance was not required. ICF international approved all the DHS surveys and ensured that the study follows the U.S. Department of Health and Human Services rules for respecting the rights of human subjects. For more details related to ethical issues, readers can visit http://goo.gl/ny8T6X.

\section{Results}

\section{Background characteristics of the sampled population}

In total, 89,029 married women were included in the analysis. Nearly $7.7 \%$ of the respondents were young women aged between 15 and 19 years, and the majority were $25-29$ years $(20.45 \%)$. Over half $(78.8 \%)$ of the respondents were rural residents. About $82 \%$ of respondents and $79.4 \%$ of their husbands had no formal education. Regarding women empowerment, about $88 \%$ of married women had no decision-making power for at least one of the three decision-making parameters; their own health, to purchase large household expenses, and to visit families or relatives. Approximately $46.3 \%$ of married women accepted or justified wife-beating for at least one of the five reasons; burning food, arguing with husband, going out without telling their husband, neglecting children, and refusing sexual intercourse.

\section{Prevalence of anemia among women in sub-Saharan Africa}

As shown in Fig. 1, the pooled result shows that $49.7 \%$ of married women in the reproductive age groups were anemic. Of these, $1.04 \%$ and $15.05 \%$ were severely and moderately anemic respectively, and the rest $33.61 \%$ were mildly anemic (Fig. 1). 
Regarding the prevalence of anemia across countries, the study shows that the highest prevalences of anemia were in Mali (64.3\%), Gambia (60.9\%), Gabon (59.6\%), and Benin (58.4\%). On the other hand, lower prevalences of anemia was reported in Rwanda (18.2\%), Zimbabwe (24.1\%), Ethiopia (26.3\%), and Zambia (28.5\%) respectively (Fig. 2).

\section{Distribution of prevalence of anemia across explanatory variables}

As shown in Table 2, anemia prevalence varied across socio-demographic and socio-economic variables. For instance, about $48.4 \%$ of married women who had not attained formal education were anemic, while $30 \%$ of married women who attended higher schools were anemic. Similarly, nearly half (49.4\%) of women whose husbands had no formal education were anemic and it lowered to $34.7 \%$ among married women whose husbands had higher education. The prevalence of anemia also varied from approximately $45.5 \%$ to $34.2 \%$ among married women in the poorest and richest households respectively. Additionally, anemia prevalence varied based on religious affiliation. For instance, more than half $(51.1 \%)$ of married
Muslim women were anemic, while the prevalence lowered to about $35.3 \%$ among married women who were Christians (Table 2).

\section{Factors associated with anemia among women in sub- Saharan Africa \\ Bivariate logistic regression results}

As shown in Table 3, several factors such as women's age, women's educational level, husbands' educational level, women's occupation, wealth index, reading of newspaper, listening to radio, watching television, place of residence, improved sanitation, contraceptive use, and religion were associated with anemia among married women in the bivariate logistic regression model (Table 3).

\section{Multivariate logistic regression results}

We observed that husbands' educational level, wealth index, contraceptive use, and religion were the main factors associated with anemia among married women. More specifically, the study shows lower odds of anemia among married women whose husbands had primary education ( $\mathrm{aOR}=0.84,95 \% \mathrm{CI}$; 0.71-0.99) as compared to married women whose husbands had no formal education. Moreover, we found lower odds of anemia

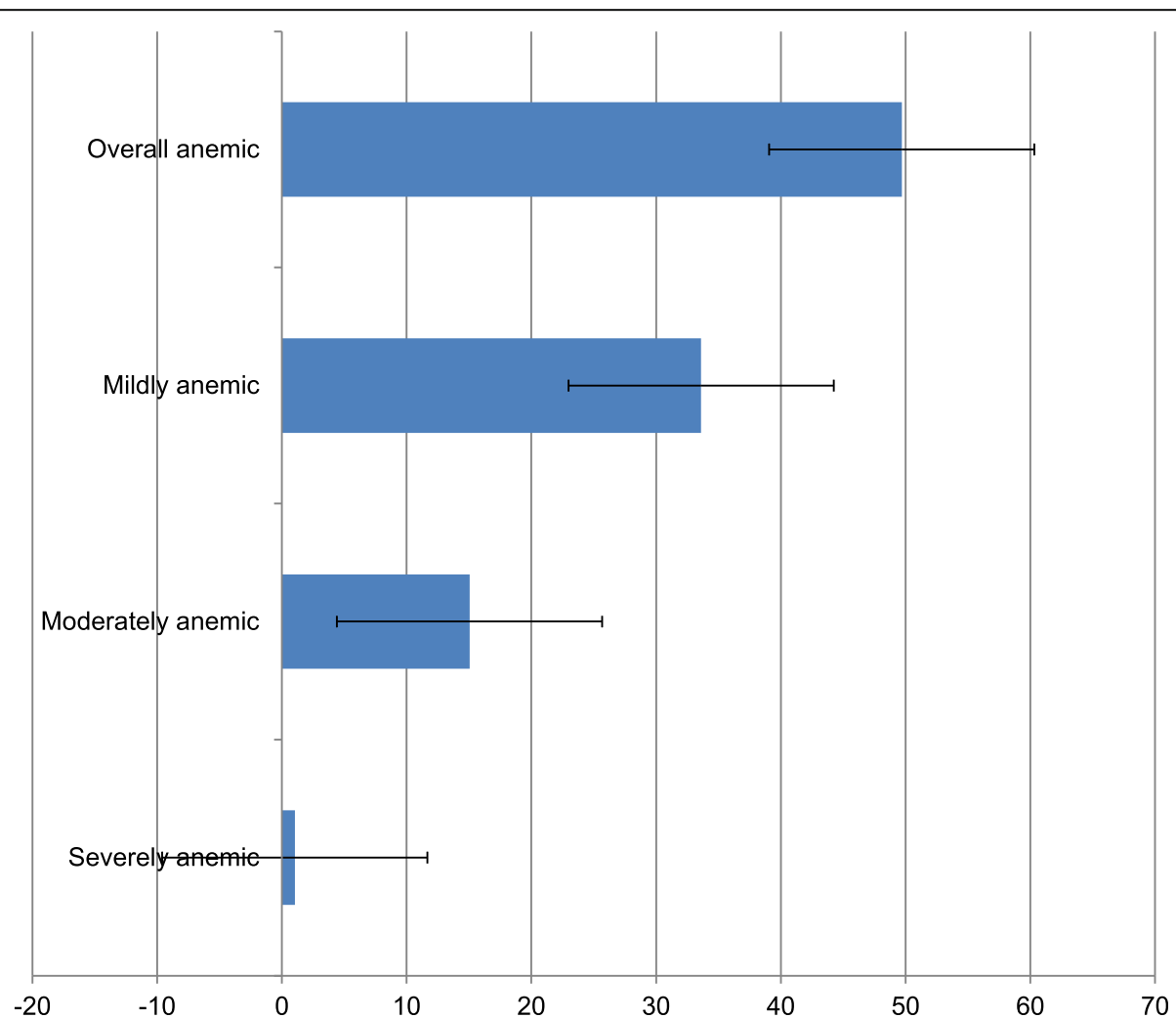

Fig. 1 Prevalence of anemia among married women in the reproductive age groups (15-49 years): Evidence from pooled results of DHSs of 19 SSA countries 


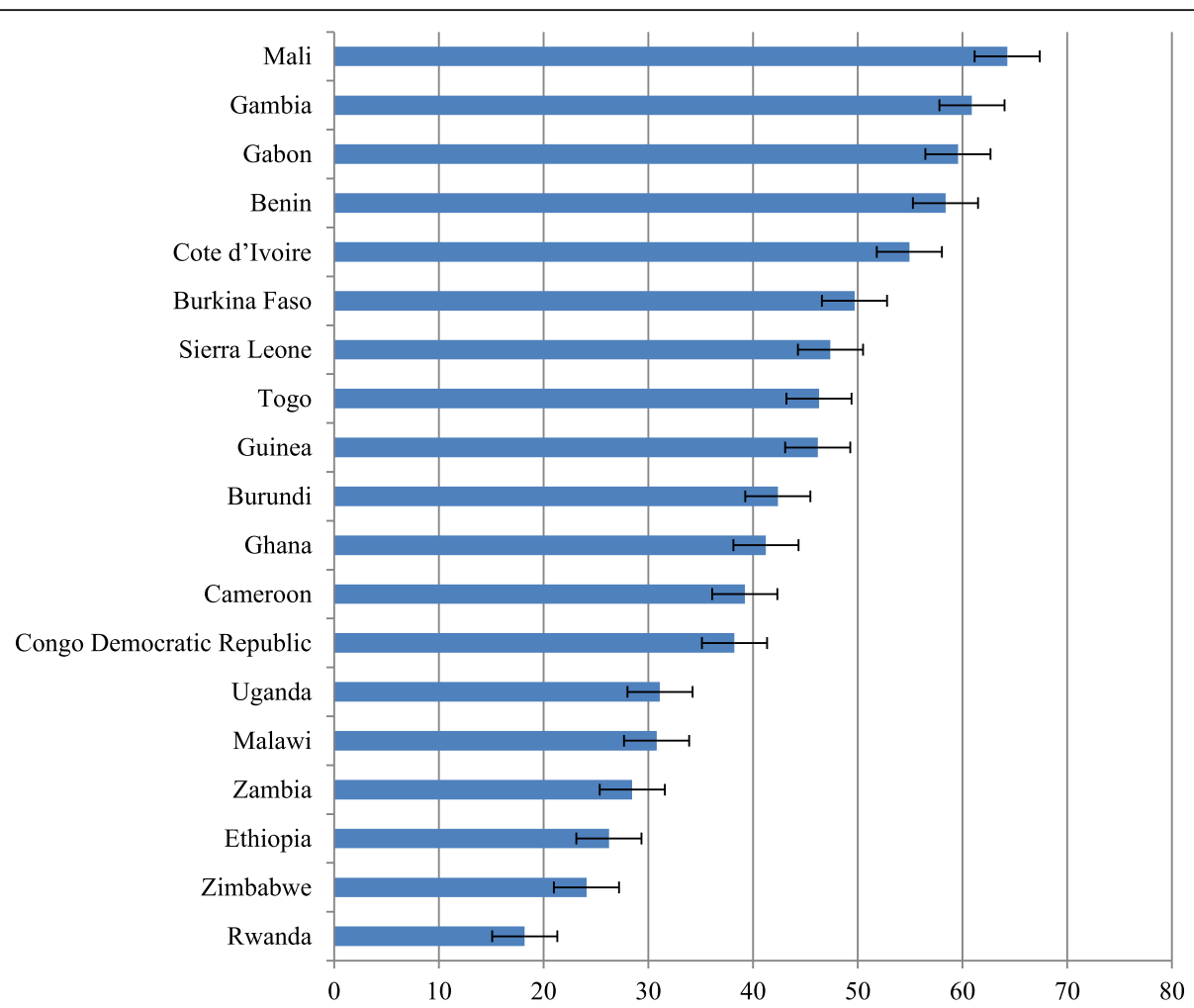

Fig. 2 Prevalence of anemia among married women in the reproductive age groups (15-49years) across 19 sub-Saharan African countries

among married from the middle $(\mathrm{aOR}=0.81,95 \% \mathrm{CI}$; $0.68-0.96)$, richer $(\mathrm{aOR}=0.69,95 \% \mathrm{CI} ; 0.57-0.84)$, and richest $(\mathrm{aOR}=0.68,95 \% \mathrm{CI} ; 0.51-0.91)$ wealth index as compared to married women in the poorest wealth index. Again, the study shows lower odds of anemia among married women who were currently using modern contraceptives $(\mathrm{aOR}=0.68,95 \% \mathrm{CI}$; 0.56-0.81) as compared to married women who were not using. Finally, the study shows higher odds of anemia among married women who belonged to the Islamic faith $(\mathrm{aOR}=1.27,95 \% \mathrm{CI} ; 1.11-1.46)$ as compared to married women who belonged to the Christian faith. Lower odds of anemia occurred among married women who belonged to other religions $(\mathrm{aOR}=0.73,95 \% \mathrm{CI} ; 0.59-0.90)$ as compared to married women who proffered the Christian faith (Table 4).

\section{Discussion}

This study examined the prevalence of anemia and its associated factors among married women in 19 countries in SSA. The pooled analysis shows $49.7 \%$ of married women in the studied countries were anemic. Of these, $1.04 \%$ and $15.05 \%$ were severely and moderately anemic respectively, and the rest $33.61 \%$ were mildly anemic. The prevalence from this study is higher as compared to those reported in a recent study in East Africa [28] that was $34 \%$ but slightly lowered as compared to the study in seven South and Southeast Asian Countries (52.5\%) [33]. The difference in prevalence was probably due to differences in the target population as reported by prior studies (married women had higher odds of being anemic as compared to never-married women) [28]. Again, methodological variations applied in the two studies and differences in the number of countries involved in the analysis might explain the differences in the findings. Out of the 19 studied countries, the lowest prevalence of anemia was reported in Rwanda (18.2\%) and the highest prevalence was in Mali (64.3\%). The variation of anemia might be due to differences in socioeconomic and other factors linked to anemia across countries $[28,33]$.

Consistent with previous studies in Ethiopia [3], India [34], and in Port Blair, Andaman, and Nicobar Islands [35], we found that the odds of anemia among married women whose husbands were educated were lower as compared to married women whose husbands had no formal education. This could be due to better receptive capacities of advice from healthcare workers and other sources regarding the prevention of anemia [34]. Educated 
Table 2 Background characteristics of respondents and distribution of anemia across explanatory variables: Evidence from DHSs of 19 sub-Saharan African countries

\begin{tabular}{|c|c|c|c|c|}
\hline \multirow[t]{2}{*}{ Variables } & \multirow{2}{*}{$\begin{array}{l}\text { Frequency } \\
\text { (Weighted \%) }\end{array}$} & \multicolumn{2}{|l|}{ Anemia } & \multirow[t]{2}{*}{ Chi-square, $P$-value } \\
\hline & & No, Frequency (Weighted \%) & Yes, Frequency (Weighted \%) & \\
\hline Age in years & & & & $x^{2}=108.13, p<0.001$ \\
\hline $15-19$ & $10,811(7.69)$ & $2992(52.81)$ & $2674(47.19)$ & \\
\hline $20-24$ & $29,487(19.80)$ & $9183(58.70)$ & $6462(41.30)$ & \\
\hline $25-29$ & $35,814(20.45)$ & $11,310(59.35)$ & $7746(40.65)$ & \\
\hline $30-34$ & $31,562(18.09)$ & $10,079(60.22)$ & $6658(39.78)$ & \\
\hline $35-39$ & $26,553(13.99)$ & $8301(58.74)$ & $5831(41.26)$ & \\
\hline $40-44$ & $18,935(11.39)$ & $5917(58.55)$ & $4189(41.45)$ & \\
\hline $45-49$ & $14,431(8.60)$ & $4639(60.35)$ & $3048(39.65)$ & \\
\hline Women's educational level & & & & $x^{2}=1400, p<0.001$ \\
\hline No formal education & $71,213(82.01)$ & $19,126(51.57)$ & $17,959(48.43)$ & \\
\hline Primary school & $55,720(11.12)$ & $18,580(64.08)$ & $10,414(35.92)$ & \\
\hline Secondary school & $35,524(6.06)$ & $12,764(63.31)$ & $7398(36.69)$ & \\
\hline Higher & $5136(0.8)$ & $1951(69.98)$ & 837 (30.02) & \\
\hline Husband's educational level & & & & $x^{2}=1500, p<0.001$ \\
\hline No formal education & $63,323(79.43)$ & $16,577(50.58)$ & $16,200(49.42)$ & \\
\hline Primary school & $46,825(12.03)$ & $15,730(64.81)$ & $8542(35.19)$ & \\
\hline Secondary school & $45,673(7.09)$ & $15,949(62.39)$ & $9616(37.61)$ & \\
\hline Higher & $11,629(1.45)$ & $4128(65.35)$ & $2189(34.65)$ & \\
\hline Women's occupation & & & & $x^{2}=122.76, p<0.001$ \\
\hline Not working & $42,230(18.49)$ & $14,602(57.90)$ & $10,616(42.10)$ & \\
\hline Professional or technical or managerial & $5770(1.12)$ & $1917(66.45)$ & $968(33.55)$ & \\
\hline Agricultural & $66,301(49.72)$ & $19,418(58.72)$ & $13,653(41.28)$ & \\
\hline Manual & $11,985(6.98)$ & $3560(63.04)$ & $2087(36.96)$ & \\
\hline Others & $41,229(23.68)$ & $12,906(58.23)$ & $9256(41.77)$ & \\
\hline Wealth index & & & & $x 2=567.88, p<0.001$ \\
\hline Poorest & $37,255(18.68)$ & $11,192(54.54)$ & $9330(45.46)$ & \\
\hline Poor & $34,176(20.48)$ & $10,183(56.46)$ & $7852(43.54)$ & \\
\hline Middle & $32,652(20.63)$ & $9874(57.99)$ & $7152(42.01)$ & \\
\hline Rich & $31,465(20.61)$ & $10,119(60.76)$ & $6536(39.24)$ & \\
\hline Richest & $32,045(19.59)$ & $11,053(65.83)$ & $5738(34.17)$ & \\
\hline Place of residence & & & & $x 2=49.70, p<0.001$ \\
\hline Urban & $51,703(21.18)$ & $16,896(60.60)$ & $10,984(39.40)$ & \\
\hline Rural & $115,890(78.82)$ & $35,525(58.10)$ & $25,624(41.90)$ & \\
\hline Reading of newspaper & & & & $X 2=22.99_{1 \prime} p<0.001$ \\
\hline No & 12,602 (94.09) & $3109(50.23)$ & $3081(49.77)$ & \\
\hline Yes & $790(5.91)$ & 239 (62.89) & $141(37.11)$ & \\
\hline Listening to radio & & & & $x 2=16.33_{\Perp} p<0.001$ \\
\hline No & $3826(30.04)$ & $887(47.03)$ & $999(52.97)$ & \\
\hline Yes & $9566(69.96)$ & $2461(52.54)$ & $2223(47.46)$ & \\
\hline Watching television & & & & $x^{2}=23.31, p<0.001$ \\
\hline No & $9773(73.18)$ & $2365(49.16)$ & $2446(50.84)$ & \\
\hline Yes & $3619(26.82)$ & $983(55.88)$ & $776(44.12)$ & \\
\hline
\end{tabular}


Table 2 Background characteristics of respondents and distribution of anemia across explanatory variables: Evidence from DHSs of 19 sub-Saharan African countries (Continued)

\begin{tabular}{|c|c|c|c|c|}
\hline \multirow[t]{2}{*}{ Variables } & \multirow{2}{*}{$\begin{array}{l}\text { Frequency } \\
\text { (Weighted \%) }\end{array}$} & \multicolumn{2}{|l|}{ Anemia } & \multirow[t]{2}{*}{ Chi-square, $P$-value } \\
\hline & & No, Frequency (Weighted \%) & Yes, Frequency (Weighted \%) & \\
\hline Sex of household head & & & & $\begin{array}{l}x 2=0.4130 \\
p=0.520\end{array}$ \\
\hline Male & $142,558(94.19)$ & $43,724(58.83)$ & $30,594(41.17)$ & \\
\hline Female & $25,632(5.81)$ & $8697(59.12)$ & $6014(40.88)$ & \\
\hline Decision making capacity & & & & $x 2=752.00, p<0.001$ \\
\hline No & $96,244(88.03)$ & $26,704(54.77)$ & $22,051(45.23)$ & \\
\hline Yes & $71,219(11.97)$ & $25,672(63.86)$ & $14,527(36.14)$ & \\
\hline Wife beating attitude & & & & $x 2=124.99, p<0.001$ \\
\hline Accept/justify & $82,620(46.33)$ & $25,723(57.06)$ & $19,357(42.94)$ & \\
\hline Disagree/Not justify & $84,903(53.67)$ & $26,678(60.75)$ & $17,237(39.25)$ & \\
\hline Parity & & & & $x^{2}=86.12, p<0.001$ \\
\hline Zero & $10,882(07.04)$ & $3110(55.32)$ & $2512(44.68)$ & \\
\hline $1-2$ & $51,939(27.75)$ & $16,740(60.44)$ & $10,956(39.56)$ & \\
\hline $3-4$ & $47,235(26.04)$ & $14,985(59.61)$ & $10,154(40.39)$ & \\
\hline $5+$ & $57,537(39.17)$ & $17,586(57.52)$ & $12,986(42.48)$ & \\
\hline Family size & & & & $x 2=83.51, p<0.001$ \\
\hline$<5$ & $52,070(25.32)$ & $17,266(61.09)$ & $10,997(38.91)$ & \\
\hline $5+$ & $115,523(74.68)$ & $35,155(57.85)$ & $25,611(42.15)$ & \\
\hline Barriers to healthcare access & & & & $x 2=162.73, p<0.001$ \\
\hline No & $56,307(20.01)$ & $18,964(61.79)$ & $11,728(38.21)$ & \\
\hline Yes & 111,204 (79.99) & $33,443(57.36)$ & $24,859(42.64)$ & \\
\hline Improved sanitation & & & & $x 2=303.33, p<0.001$ \\
\hline No & $88,343(71.25)$ & $27,212(56.25)$ & 21,167 (43.75) & \\
\hline Yes & 79,822 (28.75) & $25,200(62.01)$ & 15,436 (37.99) & \\
\hline Religion & & & & $x^{2}=2000, p<0.001$ \\
\hline Christian & $101,456(26.91)$ & $35,626(64.71)$ & $19,432(35.29)$ & \\
\hline Muslim & $58,004(63.85)$ & $14,321(48.89)$ & $14,974(51.11)$ & \\
\hline Others & $8658(9.24)$ & $2453(52.88)$ & $2186(47.12)$ & \\
\hline Contraceptive use & & & & $x^{2}=2200, p<0.001$ \\
\hline No & $124,843(84.98)$ & $35,318(54.21)$ & $29,829(45.79)$ & \\
\hline Yes & $42,750(15.02)$ & $17,103(71.61)$ & 6779 (28.39) & \\
\hline
\end{tabular}

Ref references, COR crude Odd Ratio, aOR adjusted Odd Ratio, * significant at $p<0.05,{ }^{* *}$ significant at $p<0.01,{ }^{* * *}$ significant at $p<0.001$.

husbands might encourage their wives to use modern healthcare services such as contraceptives, antenatal and postnatal care that in turn reduce the odds of the prevalence of anemia $[3,36]$.

The present study showed lower odds of anemia among married women who were in higher socioeconomic status. Previous studies in Rwanda [23, 26], Ethiopia [24], and Uganda [27] documented comparable findings. The plausible reason could be the association between socioeconomic status and intake of a healthy diet, lower chance of infection, and better access and utilization of healthcare services [37-39]. The individuals in higher socioeconomic class have higher capacities of purchasing sufficient and various foods that lead them to have a lower prevalence of anemia [28].

This study observed lower odds of anemia among married women who were currently using modern contraceptives as compared to married women who were not using a modern contraceptive. Consistent findings were reported in Ethiopia [25, 28], Rwanda [26], and 24 sub-Saharan African countries [40]. The possible reason for this could be due to modern contraceptives especially 
Table 3 Bivariate logistic regression results for factors associated with anemia among married women: Evidence from DHSs of 19 sub-Saharan African countries

\begin{tabular}{|c|c|c|}
\hline Variables & COR[95\% Cl] & $P$-value \\
\hline \multicolumn{3}{|l|}{ Age in years } \\
\hline $15-19$ & Ref & \\
\hline $20-24$ & $0.79(0.63-0.99)^{*}$ & 0.047 \\
\hline $25-29$ & $0.79(0.63-0.99)^{*}$ & 0.041 \\
\hline $30-34$ & $0.86(0.68-1.08)$ & 0.197 \\
\hline $35-39$ & $0.79(0.64-0.98)^{*}$ & 0.039 \\
\hline $40-44$ & $0.86(0.67-1.11)$ & 0.277 \\
\hline $45-49$ & $0.73(0.56-0.95)^{*}$ & 0.021 \\
\hline \multicolumn{3}{|l|}{ Women's educational level } \\
\hline No formal education & Ref & \\
\hline Primary school & $0.72(0.60-0.86)^{* * *}$ & $p<0.001$ \\
\hline Secondary school & $0.49(0.38-0.63)^{* * *}$ & $p<0.001$ \\
\hline Higher & $0.39(0.19-0.81)^{*}$ & 0.012 \\
\hline \multicolumn{3}{|l|}{ Husband's educational level } \\
\hline No formal education & Ref & \\
\hline Primary school & $0.66(0.56-0.79)^{* * *}$ & $p<0.001$ \\
\hline Secondary school & $0.53(0.42-0.68)^{* * *}$ & $p<0.001$ \\
\hline Higher & $0.45(0.21-0.95)^{*}$ & 0.037 \\
\hline \multicolumn{3}{|l|}{ Women's occupation } \\
\hline Not working & Ref & \\
\hline Professional or technical or managerial & $0.28(0.15-0.52)^{* * *}$ & $p<0.001$ \\
\hline Agricultural & $0.88(0.74-1.06)$ & 0.213 \\
\hline Manual & $0.62(0.48-0.82)^{* *}$ & 0.001 \\
\hline Others & $0.78(0.64-0.95)^{*}$ & 0.016 \\
\hline \multicolumn{3}{|l|}{ Wealth index } \\
\hline Poorest & Ref & \\
\hline Poor & $0.92(0.77-1.11)$ & 0.434 \\
\hline Middle & $0.83(0.70-0.99)^{*}$ & 0.047 \\
\hline Rich & $0.67(0.56-0.81)^{* * *}$ & $p<0.001$ \\
\hline Richest & $0.52(0.42-0.64)^{* * *}$ & $p<0.001$ \\
\hline \multicolumn{3}{|l|}{ Reading of newspaper } \\
\hline \multicolumn{3}{|l|}{ No } \\
\hline Yes & $0.53(0.39-0.73)^{* * *}$ & $p<0.001$ \\
\hline \multicolumn{3}{|l|}{ Listening to radio } \\
\hline \multicolumn{3}{|l|}{ No } \\
\hline Yes & $0.83(0.72-0.94)^{* *}$ & 0.006 \\
\hline \multicolumn{3}{|l|}{ Watching television } \\
\hline \multicolumn{3}{|l|}{ No } \\
\hline Yes & $0.72(0.63-0.83)^{* * *}$ & $p<0.001$ \\
\hline \multicolumn{3}{|l|}{ Place of residence } \\
\hline Urban & Ref & \\
\hline Rural & $1.55(1.32-1.83)^{* * *}$ & $p<0.001$ \\
\hline
\end{tabular}


Table 3 Bivariate logistic regression results for factors associated with anemia among married women: Evidence from DHSs of 19 sub-Saharan African countries (Continued)

\begin{tabular}{|c|c|c|}
\hline Variables & cOR $[95 \% \mathrm{Cl}]$ & $P$-value \\
\hline \multicolumn{3}{|l|}{ Decision making } \\
\hline No & Ref & \\
\hline Yes & $0.90(0.75-1.08)$ & 0.268 \\
\hline \multicolumn{3}{|l|}{ Wife beating attitude } \\
\hline Accept/justify & Ref & \\
\hline Disagree/Not justify & $1.03(0.92-1.15)$ & 0.553 \\
\hline \multicolumn{3}{|l|}{ Family size } \\
\hline$<5$ & Ref & \\
\hline $5+$ & $0.96(0.84-1.09)$ & 0.556 \\
\hline \multicolumn{3}{|c|}{ Barriers to healthcare access } \\
\hline No & Ref & \\
\hline Yes & $1.14(0.99-1.32)$ & 0.060 \\
\hline \multicolumn{3}{|l|}{ Improved sanitation } \\
\hline No & Ref & \\
\hline Yes & $0.65(0.56-0.76)^{* * *}$ & $p<0.001$ \\
\hline \multicolumn{3}{|l|}{ Contraceptive use } \\
\hline No & Ref & \\
\hline Yes & $0.56(0.47-0.67)^{* * *}$ & $p<0.001$ \\
\hline \multicolumn{3}{|l|}{ Religion } \\
\hline Christian & Ref & \\
\hline Muslim & $1.43(1.25-1.64)^{* * *}$ & $p<0.001$ \\
\hline Others & $0.92(0.75-1.13)$ & 0.444 \\
\hline \multicolumn{3}{|l|}{ Parity } \\
\hline Zero & Ref & \\
\hline $1-2$ & $1.15(0.90-1.46)$ & 0.242 \\
\hline $3-4$ & $1.12(0.87-1.43)$ & 0.358 \\
\hline $5+$ & $1.16(0.91-1.47)$ & 0.225 \\
\hline
\end{tabular}

Ref references, COR crude Odd Ratio, aOR adjusted Odd Ratio, ${ }^{*}$ significant at $p<0.05,{ }^{* *}$ significant at $p<0.01,{ }^{* * *}$ significant at $p<0.001$.

the hormonal methods reducing blood loss associated with menstruation that again decrease susceptibility to anemia [41, 42]. In addition, modern contraceptive use prevents blood loss and related complications during pregnancy, childbirth, and the postpartum period [28].

In this study, we found that religion was statistically significantly associated with anemia as reported in previous studies in Ghana [43] India [34] and Rajasthan [44]. The first reason might be related to religious beliefs and /or cultural practices in restriction of some type of foods especially during pregnancy [43] and due to variation in socioeconomic status [44].

\section{Strengths and limitations of the study}

The study examined the prevalence of anemia and its associated factors using nationally representative data from multiple countries which may be considered as a strength of the study. However, this study should be seen with the following limitations. First, the crosssectional nature of the study design, makes measuring a cause-effect relationship impossible and self-reported data may be affected by recall bias from the participants. Second, some explanatory variables which influence anemia, such as malaria and parasitic infection, were not available in the dataset. Third, the interval between the oldest survey and the most recent survey was 9 years, which is a relatively long duration, and due to the time effect comparison across countries might not always be possible.

\section{Conclusion}

This study examined the prevalence of anemia among women and its associated factors in SSA. The study showed that approximately half of the married women 
Table 4 Multivariable logistic regression results for factors associated with anemia among married women: Evidence from the DHSs of 19 sub-Saharan African countries

\begin{tabular}{l} 
Variables \\
\hline Age in years \\
$15-19$ \\
$20-24$ \\
$25-29$ \\
$30-34$ \\
$35-39$ \\
$40-44$ \\
$45-49$ \\
Women's educational leve \\
No formal education \\
Primary school \\
Secondary school \\
Higher \\
Husband's educational leve \\
No formal education \\
Primary school \\
Secondary school \\
Higher
\end{tabular}

aOR $[95 \% \mathrm{Cl}]$

$P$-value

Age in years

Women's occupation

Not working

Professional or technical or managerial

Agricultural

Manual

Others

\section{Wealth index}

Poorest

Poor

Middle

Rich

Richest

\section{Reading of newspaper}

No

Yes

Listening to radio

No

Yes

Watching television

No

Yes

Place of residence

Urban

Rural
Ref

$0.89(0.71-1.12)$

0.360

$0.92(0.73-1.16)$

0.515

$0.99(0.78-1.25)$

0.975

$0.89(0.71-1.12)$

0.348

$0.97(0.74-1.27)$

0.853

$0.79(0.60-1.04)$

0.094

Ref

$0.91(0.76-1.10)$

0.380

0.080

$0.71(0.36-1.40)$

0.333

Ref

$0.84(0.71-0.99)^{*}$

0.045

$0.87(0.66-1.14)$

0.314

$0.95(0.47-1.91)$

0.895

Ref

0.55 (0.30-1.01)

0.055

$0.82(0.67-1.01)$

0.074

$0.76(0.58-1.00)$

0.053

$0.89(0.72-1.08)$

0.256

Ref

$0.90(0.75-1.08)$

0.286

$0.81(0.68-0.96)^{*}$

0.020

$0.69(0.57-0.84)^{* * *}$

0.000

$0.68(0.51-0.91)^{*}$

0.011

Ref

$1.09(0.76-1.56)$

Ref

$0.94(0.82-1.07)$

0.400

Ref

$0.99(0.85-1.15)$

0.925

Ref

1.07 (0.88-1.30)
$0.74(0.53-1.03)$ 
Table 4 Multivariable logistic regression results for factors associated with anemia among married women: Evidence from the DHSs of 19 sub-Saharan African countries (Continued)

\begin{tabular}{|c|c|c|}
\hline Variables & aOR[95\% Cl] & $P$-value \\
\hline \multicolumn{3}{|c|}{ Improved sanitation } \\
\hline No & Ref & \\
\hline Yes & $0.92(0.75-1.14)$ & 0.478 \\
\hline \multicolumn{3}{|c|}{ Contraceptive use } \\
\hline No & Ref & \\
\hline Yes & $0.68(0.56-0.81)^{* * *}$ & 0.000 \\
\hline \multicolumn{3}{|l|}{ Religion } \\
\hline Christian & Ref & \\
\hline Muslim & $1.27(1.11-1.46)^{* *}$ & 0.001 \\
\hline Others & $0.73(0.59-0.90)^{* *}$ & 0.003 \\
\hline
\end{tabular}

Ref references, cOR crude Odd Ratio, aOR adjusted Odd Ratio, ${ }^{*}$ significant at $p<0.05,{ }^{* *}$ significant at $p<0.01,{ }^{* * *}$ significant at $p<0.001$.

had anemia. Husbands' education, wealth index, modern contraceptive use and religion were statistically significantly associated factors with anemia among married women. Consequently, national governments and other stakeholders working on women's health have to enhance husbands' education, and economic empowerment of married women, strengthen family planning services and work with religious leaders to reduce the burden of anemia in the included countries.

\section{Abbreviations}

aOR: Adjusted Odd Ratio; Cl: Confidence interval; COR: Crude Odd Ratio; DHS: Demographic and Health Surveys; EA: Enumeration Area; MLR: Multivariate Logistic Regression; PPS: Probability Proportional to Size: SDGs: Sustainable Development Goals; SSA: Sub-Saharan Africa

\section{Acknowledgments}

We acknowledge the Demographic and Health Surveys Program for making the DHS data available, and we thank the women who participated in the surveys.

\section{Authors' contributions}

SY and BZ contributed to the conception and design of the study, interpreted the data, prepared the manuscript, and led the paper. FEA, BOA, EKA, EB and AS helped with data analysis, provided technical support in interpretation of results and critically reviewed the manuscript for its intellectual content. SY had final responsibility to submit. All authors read and revised drafts of the paper and approved the final version.

\section{Funding}

No funding was received for this work.

\section{Availability of data and materials}

The datasets generated and/or analyzed during the current study are available in http://dhsprogram.com/data/available-datasets.cfm.

\section{Declarations}

Ethics approval and consent to participate

Ethics approval was not required since the data is available to the public domain.

\section{Consent for publication}

Not applicable.

\section{Competing interests}

The authors declare that they have no competing interests.

\section{Author details}

${ }^{1}$ HaSET Maternal and Child Health Research Program, Addis Ababa, Ethiopia. ${ }^{2}$ Centre for Health and Development, University of Port Harcourt, Port Harcourt, Nigeria. ${ }^{3}$ School of Public Health, University of Technology Sydney, Sydney, Australia. ${ }^{4}$ Centre For Gender and Advocacy, Takoradi Technical University, Takoradi, Ghana. ${ }^{5}$ School of International Development and Global Studies, University of Ottawa, Ottawa, Ontario, Canada. ${ }^{6}$ The George Institute for Global Health, Imperial College London, London, UK.

Received: 13 August 2021 Accepted: 10 November 2021 Published online: 29 November 2021

References

1. World Health Organization. Anaemia. Available at: https://www.who.int/hea Ith-topics/anaemia\#tab=tab_1. Accessed on 04 March 2021.

2. Hisa K, Haruna M, Hikita N, Sasagawa E, Yonezawa K, Suto M, et al. Prevalence of and factors related to anemia among Japanese adult women: secondary data analysis using health check-up database. Sci Rep. 2019;9(1): 1-8. https://doi.org/10.1038/s41598-019-52798-y.

3. Lakew Y, Biadgilign S, Haile D. Anaemia prevalence and associated factors among lactating mothers in Ethiopia: evidence from the 2005 and 2011 demographic and health surveys. BMJ Open. 2015;5:e006001. https://doi. org/10.1136/bmjopen-201400600.

4. World Health Organization. Haemoglobin concentrations for the diagnosis of anaemia and assessment of severity: World Health Organization; 2011.

5. Kassebaum NJ, Jasrasaria R, Naghavi M, Wulf SK, Johns N, Lozano R, et al. A systematic analysis of global anemia burden from 1990 to 2010. Blood. 2014;123(5):615-24.

6. Global Burden of Disease DALYs, Hale Collaborators, Murray CJ, Barber RM, Foreman KJ, Abbasoglu Ozgoren A. Global, regional, and national disability adjusted life years (DALYs) for 306 diseases and injuries and healthy life expectancy (HALE) for 188 countries, 1990-2013: Quantifying the epidemiological transition. Lancet. 2015;386(10009):2145-91.

7. Harding $\mathrm{KL}$, Aguayo VM, Namirembe G, Webb P. Determinants of anemia among women and children in Nepal and Pakistan: an analysis of recent national survey data. Matern Child Nutr. 2018;(Suppl 4(Suppl 4)):e12478. https://doi.org/10.1111/mcn.12478.

8. World Health Organization. The global prevalence of anemia in 2011, 2015. Available from at: https://www.who.int/nutrition/publications/micronutrients/ global_prevalence_anaemia_2011/en/. [Accessed on 05 Mar 2021].

9. World Bank. Prevalence of anemia among reproductive age (\% of women ages 15-49). Available at: https://data.worldbank.org/indicator/SH.ANM.A LLW.ZS. Accessed on 05 March 5, 2021.

10. Chaparro CM, Suchdev PS. Anemia epidemiology, pathophysiology, and etiology in low- and middle-income countries. Ann N Y Acad Sci. 2019; 1450(1):15-31. https://doi.org/10.1111/nyas.14092. 
11. Pasricha SR, Drakesmith H, Black J, Hipgrave D, Biggs B-A. Control of iron deficiency anemia in low- and middleincome countries. Blood. 2013;121(14): 2607-17. https://doi.org/10.1182/blood-2012-09-453522.

12. Balarajan Y, Ramakrishnan U, Ozaltin E, Shankar AH, Subramanian SV. Anaemia in low-income and middleincome countries. Lancet. 2011; 378(9809):2123-35. https://doi.org/10.1016/S0140-6736(10)62304-5.

13. Petry N, Ibironke Olofin I, Hurrell RF, Boy E, Wirth JP, Moursi M, et al. The proportion of anemia associated with iron deficiency in low, medium, and high human development index countries: a systematic analysis of national surveys. Nutrients. 2016;8(11):693. https://doi.org/10.3390/nu8110693.

14. Wirth JP, Woodruff BA, Engle-Stone R, Namaste SM, Temple VJ, Petry N, et al. Predictors of anemia in women of reproductive age: biomarkers reflecting inflammation and nutritional determinants of Anemia (BRINDA) project. Am J Clin Nutr. 2017;106(Suppl. 1):416S-27S. https://doi.org/10.3945/ajen.116.143073.

15. Pasricha SR, Low M, Thompson J, Farrell A, De-Regil LM. Iron supplementation benefits physical performance in women of reproductive age: a systematic review and meta-analysis. J Nutr. 2014;144(6):906-14. https://doi.org/10.3945/jn.113.189589.

16. Georgieff MK. Iron deficiency in pregnancy. Am J Obstet Gynecol. 2020; S0002-9378(20):30328. https://doi.org/10.1016/j.ajog.2020.03.006.

17. Juul SE, Derman RJ, Auerbach M. Perinatal iron deficiency: implications for mothers and infants. Neonatology. 2019;115(3):269-74. https://doi.org/10.11 $59 / 000495978$

18. Global anaemia reduction efforts among women of reproductive age: impact, achievement of targets and the way forward for optimizing efforts. Geneva: World Health Organization; 2020. Licence: CC BY-NC-SA 3.0 IGO.

19. Allen LH. Anemia and iron deficiency: effects on pregnancy outcome. Am J Clin Nutr. 2000;71:1280S-4S. https://doi.org/10.1093/ajen/71.5.1280s.

20. Steer PJ. Maternal hemoglobin concentration and birth weight. Am J Clin Nutr. 2000;71(5 Suppl):1285S-7S. https://doi.org/10.1093/ajcn/71.5.1285s.

21. United Nations: Transforming our world: the 2030 Agenda for Sustainable Development. Available at: https://www.un.org/ga/search/view doc.a sp?symbol=A/RES/70/1\&Lang=E. Accessed on 12 March 2021.

22. Global Nutrition Targets 2025. Anaemia policy brief. Geneva: World Health Organization; 2014 (WHO/NMH/ NHD/14.4; https://www.who.int/nutrition/ publications/globaltargets2025_policybrief_anaemia/en/. Accessed on 04 March 4, 2021

23. Habyarimana F, Zewotir T, Ramroop S. Spatial distribution and analysis of risk factors associated with Anemia among women of reproductive age: case of 2014 Rwanda demographic and health survey data. Open Public Health J. 2018;11(1):425-37.

24. Kibret KT, Chojenta C, D'Arcy E, Loxton D. Spatial distribution and determinant factors of anaemia among women of reproductive age in Ethiopia: a multilevel and spatial analysis. BMJ Open. 2019;9(4):e027276.

25. Liyew AM, Teshale AB. Individual and community level factors associated with anemia among lactating mothers in Ethiopia using data from Ethiopian demographic and health survey, 2016; a multilevel analysis. BMC Public Health. 2020;20(1):1-11.

26. Hakizimana D, Nisingizwe MP, Logan J, Wong R. Identifying risk factors of anemia among women of reproductive age in Rwanda-a cross-sectional study using secondary data from the Rwanda demographic and health survey 2014/2015. BMC Public Health. 2019;19(1):1662.

27. Nankinga O, Aguta D. Determinants of Anemia among women in Uganda: further analysis of the Uganda demographic and health surveys. BMC Public Health. 2019:19(1):1-9.

28. Teshale AB, Tesema GA, Worku MG, Yeshaw Y, Tessema ZT. Anemiaand its associated factors among women of reproductive age in eastern Africa: a multilevel mixed-effects generalized linear model. PLoS One. 2020;15(9): e0238957. https://doi.org/10.1371/journal.pone.0238957.

29. DHS Program. Methodology: survey type. Available at: https://dhsprogram. com/methodology/survey-Types/dHs.cfm. Accessed on 04 March 4, 2021.

30. Thee DHS Program- Quality information to plan, monitor and improve population, health, and nutrition programs. Available at: https://dhsprogram. com/. Accessed on 04 March 4, 2021.

31. DHS Program. Guide to DHS statistics. Analyzing DHS data. Avaialable at: https://dhsprogram.com/data/Guide-to-DHS-Statistics/Analyzing_DHS_Data. htm. Accessed on 04 March 2021

32. von Elm E, Altman DG, Egger M, Pocock SJ, Gøtzsche PC, Vandenbroucke $J P$. The strengthening the reporting of observational studies in epidemiology (STROBE) statement: quidelines for reporting observational studies. Int J Surg. 2014;12(12):1495-9.
33. Sunuwar DR, Singh DR, Chaudhary NK, Paradhan PMS, Rai P, Tiwari K, et al. Prevalence and factors associated with anemia among women of reproductive age in seven south and southeast Asian countries. Evidence from national representative surveys. PLoS One. 2020;15(8):e0236449.

34. Lokare PO, Karanjekar VD, Gattani PL, Kulkarni AP. A study of prevalence of anemia and sociodemographic factors associated with anemia among pregnant women in Aurangabad city, India. Ann Nigerian Med. 2012;6(1):15.

35. Mehrotra M, Yadav S, Deshpande A, Mehrotra H. A study of the prevalence of anemia and associated sociodemographic factors in pregnant women in Port Blair, Andaman and Nicobar Islands. J Family Med Prim Care. 2018;7(6): 1288-93.

36. Levtov R, Van Der Gaag V, Greene M, Michael K, Barker G. State of the World's fathers. In: A MenCare advocacy publication. Washington, DC: Promundo; 2015.

37. Soofi S, Khan GN, Sadiq K, Ariff S, Habib A, Kureishy S, et al. Prevalence and possible factors associated with anaemia, and vitamin B 12 and folate deficiencies in women of reproductive age in Pakistan: analysis of nationallevel secondary survey data. BMJ Open. 2017;7(12):e018007.

38. Arpey NC, Gaglioti AH, Rosenbaum ME. How socioeconomic status affects patient perceptions of health care: a qualitative study. J Prim Care Community Health. 2017:8(3):169-75.

39. Apouey $\mathrm{BH}$. Health policies and the relationships between socioeconomic status, access to health care, and health. Isr J Health Policy Res. 2013:2(1):50.

40. Gebremedhin SK, Asefa A. Association between type of contraceptive use and haemoglobin status among women of reproductive age in 24 subSaharan Africa countries. BMJ Sex Reprod Health. 2019;45(1):54-60.

41. Miller $L$, Hughes JP. Continuous combination oral contraceptive pills to eliminate withdrawal bleeding: a randomized trial. Obstet Gynecol. 2003; 101(4):653-61.

42. Glasier AF, Smith KB, Van der Spuy ZM, Ho PC, Cheng L, Dada K, et al. Amenorrhea associated with contraception-an international study on acceptability. Contraception. 2003;67(1):1-8.

43. Dwumfour-Asare B, Kwapong MA. Anaemia awareness, beliefs and practices among pregnant women: a baseline assessment at Brosankro community in Ghana. J Natural Sci Res. 2013;3:15.

44. Bansal B, Takkar J, Soni ND, Agrawal DK, Agarwal S. Comparative study of prevalence of anemia in muslim and non-muslim pregnant women of western Rajasthan. Int J Res Health Sci (Supplement). 2013;1(2):47-52.

\section{Publisher's Note}

Springer Nature remains neutral with regard to jurisdictional claims in published maps and institutional affiliations.

Ready to submit your research? Choose BMC and benefit from:

- fast, convenient online submission

- thorough peer review by experienced researchers in your field

- rapid publication on acceptance

- support for research data, including large and complex data types

- gold Open Access which fosters wider collaboration and increased citations

- maximum visibility for your research: over $100 \mathrm{M}$ website views per year

At $\mathrm{BMC}$, research is always in progress.

Learn more biomedcentral.com/submission 